\title{
Leonardo Bruni, a tradução "correta" e a abordagem clássica dos humanistas ${ }^{1}$
}

Paulo Sidnei de Lima e Yuxi Liang*

\section{A polêmica de Bruni e o tratado De interpretatione recta}

Por mais que se considerem as inovações na História humana dignas e louváveis, as mesmas tendem a surgir sempre confrontadas por resistência veemente. Esta é a situação em que Leonardo Bruni se encontra no início do séc. $\mathrm{XV}$, quando lhe fizeram sérias acusações motivadas por sua crítica aos erros da tradução antiga da obra aristotélica Ética a Nicômaco e ao que ele considerou inaptidão do tradutor antigo.

É nesse contexto que o tratado De interpretatione recta de Bruni (1420) foi escrito. As propostas de Bruni sobre a tradução, para generalizar, são congruentes com os pensamentos que o Humanismo vai desenvolvendo e exercitando nesse campo (FURLAN, 2011), em oposição às concepções e práticas tradutórias medievais.

Leonardo Bruni Aretino (ca. 1370 - 1444) termina sua tradução da Ética a Nicômaco entre 1416 e 1417 anexando mais tarde a uma edição dessa tradução o texto De interpretatione recta, elaborado entre 1420 e 1426 . A respeito das polêmicas que Bruni suscitou, Hankins as divide em duas fases: a primeira teria durado quase uma década após a publicação da tradução, sendo que essas objeções foram dirigidas a Bruni pelo monge bizantino

\footnotetext{
${ }^{1}$ Este artigo é o fruto de colaboração dos autores, desenvolvido a partir da versão conjunta de suas monografias entregues no final do curso "Tradução e Filologia: a Transmissão de Textos Filosóficos e Científicos à Idade Média", ministrado pelo Prof. Dr. Luiz Antônio Lindo, no primeiro semestre de 2018. * Universidade de São Paulo (USP).
} 
Demetrio Scarano. A segunda "teve lugar entre os anos de 1436 e 1438 e foi chamada de 'controversia alphonsiana', de Alfonso de Cartagena, que era o principal opositor de Bruni". (HANKINS, 2001, p. 134 apud MARASSI, 2009, p. 127 , nota)

Abordaremos, em seguida, estas duas fases respectivamente. A crítica dirigida a Bruni no primeiro momento da polêmica considera inclusive uma impiedade ${ }^{2}$ as suas refutações à boa fé do antigo tradutor, Roberto Grosseteste (1175 - 1253). O campo em que os primeiros opositores de Bruni buscam combatê-lo é, conforme discutiremos mais adiante, o da "ética das virtudes", um conceito estabelecido a partir da recepção tardia de Aristóteles na Europa, no âmbito dos estudos da Escolástica, e desse ponto de vista o comportamento de Bruni era ímpio, desrespeitoso, nada virtuoso, e o do antiquus interpres era digno de elogio, pois ele havia divulgado em seu trabalho o quanto pudera saber.

Assim, no início de seu tratado, Bruni admite "ter sido um tanto veemente ao repreendê-lo [ao antigo tradutor]"3 , e se defende alegando que "não ultrapassamos o limite", "conservamos a moderação e a humanidade" 4 . Portanto, Bruni habilmente afasta o debate do campo da ética das virtudes para, em seguida, levá-lo para o das artes, das competências de um tradutor, transferindo astutamente o foco da polêmica do argumentum ad hominem ao ad rem.

Em seguida, Bruni passa a elencar o conteúdo programático de seu texto, dizendo que discorrerá sobre o que ele pensa do método de traduzir, as repreensões "merecidamente" feitas ao antigo tradutor, e que, ao repreender os erros dele, observou o costume de "homens doutíssimos".

Ao elucidar os princípios de uma tradução correta, o humanista postula que não basta a um tradutor a erudição para se aplicar ao trabalho de traduzir as obras dos homens ilustres. Assim como é indispensável, mas

\footnotetext{
2 Has redargutiones meas nonnulli, ut audio, carpunt quasi nimium inclementes. A tradução de Furlan: "Alguns, segundo tenho ouvido, criticam estas minhas refutações como demasiado impiedosas". Usamos aqui o termo lexical derivado da palavra "impiedosas".

3 "Ego autem fateor me paulo uehementiorem in reprehendendo fuisse..." (De Interpretatione Recta, I, trad. Mauri Furlan).

4 "Sed non sumus transgressi modum iudicio nostro, sed quamuis indignantes modestiam tamen humanitatemque seruauimus." (De Interpretatione Recta, I, trad. Mauri Furlan).
} 
não de todo suficiente, o conhecimento do grego e do latim, da mesma maneira é pré-requisito um conhecimento aprofundado do estilo e do pensamento de cada um destes autores, a ponto de poderem seguir fielmente cada passo do pensador com a sua tradução, pois, sem atender a estes pressupostos, o tradutor deformaria a obra dos grandes homens com o seu trabalho, prejudicando-as irreparavelmente. Para reforçar o status de sua crítica contra o antigo tradutor, o humanista citou, na segunda parte do tratado, exemplos de uma tradução da Política de Aristóteles que ele julga ter sido feita pelo mesmo erudito, cuja tradução é caracterizada pelo humanista de "delírio e barbárie" 5 que prejudica a elegância de Aristóteles.

A fim de desdobrar o motivo do "Bruni indignado" e a origem da polêmica acerca de tradução de Aristóteles, julgamos necessário perpassar nos tempos anteriores a Bruni e observar como a transmissão das obras aristotélicas e a recepção de suas sentenças na Europa garantiram ao filósofo tamanho e inegável prestígio.

\section{O prestígio de Aristóteles e da Ética na Idade Média}

Aristóteles foi definido como "O Filósofo" por eruditos de várias nações e tradições e também era assim reverenciado pelos expoentes da tradição escolástica, como Tomás de Aquino. Como o grego não era a língua de erudição na Europa da Idade Média, a recepção das obras de Aristóteles e de outros pensadores gregos se deu via tradução para o latim, um latim científico, uma língua dominada apenas pelos eruditos e eclesiásticos e que é construída e equipada a partir do próprio ato de tradução dessas obras gregas a partir do árabe (JOLIVET, 1988, p. 120 - 122).

Segundo Kristeller (1993, p. 190) muito pouco se traduziu para o latim até o século XI porque "ao término da Antiguidade e início da Idade Média o Ocidente latino não só se separou do Oriente greco-bizantino em sentido político como perdeu todo o conhecimento da língua grega e, por isso mesmo, todo o acesso à cultura grega antiga."

\footnotetext{
${ }^{5}$ Bruni reclama, mais de uma vez no tratado, da incompetência do tradutor da Política, e.g. "Deus immortalis, quis haec intelliget? quis hanc interpretationem ac non potius delirationem ac barbariem uocitabit?" (De Interpretatione Recta, II, trad. Mauri Furlan)
} 
$\mathrm{O}$ avanço que permite ao latim medieval a aquisição de termos para a tradução e o debate da filosofia se dá pouco depois de estabelecida a tradição de tradução dos tradutores e comentadores árabes, escola que conta, dentre muitos outros, com os trabalhos de Al-Farabi (872 - 951), Avicena (980 - 1037), Al-Ghazali (1058 - 1111) e Averróis (1126 - 1198). Eles gozam de elevada reputação entre os eruditos da Idade Média. Um exemplo é DanteAlighieri, que menciona Avicena e Al-Ghazali ao lado de Platão em $O$ Convívio (2, xiii, 5; 4, xxi, 2).

Esta recepção em língua latina facultou e propiciou em muito o trabalho dos comentaristas de filosofia e teologia conhecidos como glossatori, especialmente depois das traduções de Gerardo de Cremona (1114 - 1187), Roberto Grosseteste (1168 - 1253) e William de Moerbeke (c. 1215 - 1286). Roberto Grosseteste teria feito a sua tradução da Ética a Nicômaco de Aristóteles a partir de um manuscrito antigo de Burgúndio de Pisa. Segundo Martins (2011, p. 57, 58), William Moerbeke faz uma revisão do texto de Grosseteste e a publica em 1246, ao que se segue o estudo e comentário desta tradução latina por Alberto Magno entre 1248 e 1252, na obra denominada Super-Ethica. Este seu trabalho foi seguido pelos estudos e comentários de Tomás de Aquino (1225 - 1274).

Um tema que se destaca nos comentários e debates suscitados a partir do trabalho dos glossatori se embasa na discussão das virtudes morais e intelectuais colocada pela Ética a Nicômaco. Este debate, que é da maior importância dentro do pensamento escolástico, leva aos mais diversos temas correlatos, como a questão da queda do ser humano, do pecado, da visão beatífica, da felicidade humana, do supremo bem, a girarem em torno do que se denominou a "ética das virtudes". Desse contexto podemos ter uma noção de como foi prestigiada a recepção da Ética a Nicômaco e da reputação de seus tradutores, Moerbeke e Grosseteste, que produziram uma tradução que era a base para todas estas considerações.

Isso posto, é fácil perceber como uma crítica mais direta ao trabalho de tradução do "antiquus interpres", Roberto Grosseteste, gerou indignação entre aqueles que se posicionaram contra Leonardo Bruni, autor das críticas e de uma tradução que propunha muitas inovações e rompia com vários preceitos daquela tradição. 


\section{Da tradução medieval à tradução "Bruniana"}

De acordo com Kristeller (1993, p. 192-193), as traduções do grego ao latim até o séc. XIV eram feitas "sem nenhuma sensibilidade pela sintaxe ou a fraseologia do grego clássico". O resultado era traduções com um conteúdo bastante limitado, que abrangiam quase que exclusivamente os campos da teologia, das ciências e da filosofia.

As traduções eram de caráter extremamente utilitário e nelas a eloquência adquire um sentido meramente instrumental. A difusão do cristianismo gera a necessidade de tradução dos livros sagrados e das obras dos Padres apostólicos, sendo que a fé na inspiração divina destes escritos exige uma reprodução fiel dos originais. Desenvolve-se um grande literalismo nestas traduções, especialmente as de textos religiosos, e desaparece o conceito negativo existente em Cícero da tradução ad verbum. Ainda assim, inicia-se uma diferenciação da tradução sacra da profana, com atribuição de maior necessidade de literalidade à primeira que à segunda (FURLAN, 2003 p. 10).

A tradução para os autores clássicos era um exercício estilístico para produção artística. Com efeito, aemulatio, para os romanos, é um ato de imitar a fim de competir com os escritores ilustres helênicos e daí produzir obras literárias em latim dignas de apreciação do público-alvo bilíngue. Um exemploe Aulo Gélio, que elogia as Bucólicas de Virgílio em comparação com Teócrito, a contrapartida helênica da poesia bucólica. ${ }^{6}$

Já a tradução na Idade Média, especialmente em seus primeiros séculos, carece de valor literário. Segundo Folena (1991, p. 10) “perde-se o valor dinâmico da aemulatio e da tradução artística e o conceito de traduzir se expande para aquele da pura transmissão de conteúdos, da reelaboração e da metamorfose do texto."

Gradualmente se avança até a concepção de tradução como enarratio, na qual o comentário praticamente substitui o texto original. De acordo com Deslile \& Woodsworth (1995, p. 78), “na Idade Média, a tradução em língua

\footnotetext{
${ }^{6}$ Cf. Noctes Atticae, XI, 9. The Latin Library
} 
vulgar dos autores clássicos é uma atividade indissociável da exegese, do comentário e da apropriação textual".

Assim, a enarratio, embora não seja um elemento exclusivo da Idade Média, caracteriza o período enquanto recurso de assimilação e da tentativa de explicar a Antiguidade. O texto não era considerado algo imutável e definitivo, mas como objeto de interpretação contínua e mutável segundo o julgamento e as condições de compreensão de cada geração de expositores, valorizando-se a possibilidade de enriquecê-lo, corrigi-lo e variá-lo. A atividade literária que em princípio careceria de criatividade acaba apresentando-se altamente criativa, sobretudo em seus meios de efetivação (FURLAN, 2003, p. 11).

De uma forma um pouco mais concisa, estão postos os elementos pelos quais a erudição medieval buscou se apropriar dos textos clássicos, e não apenas deles, mas também das formas como a Idade Média procurou se apropriar da própria retórica clássica (especificamente de Cícero) ou rechaçá-la. Esta luta está presente em São Jerônimo, quando comparamos os elementos postulados em sua epístola A Pamacchio, uma defesa da tradução pelo sentido em função do conteúdo, servindo-se de recursos gramáticoretóricos como a enarratio e a explanatio, mas de forma distinta do uso da retórica que Cícero faz, que traduz imitando, latinizando, emulando. Jerônimo repõe o fidus interpres ciceroniano, o tradutor literal e sem arte, pelo tradutor que busca preservar o sentido textual, a ueritas (FURLAN, 2003, p. 14).

No que diz respeito a ambiguidades e inexatidões de uma tradução, a retórica clássica trata das questões de sentido a partir da perspectiva do orador. As coisas são ambíguas e o sentido está subordinado ao uso efetivo do orador. A retórica sacra medieval, por sua vez, a partir de Agostinho e seus herdeiros, trata as ambiguidades de sentido a partir da perspectiva do leitor. É responsabilidade do leitor, por meio de uma educação em uma doutrina correta, interpretar as palavras e levar em conta seu sentido. Esta compreensão do poder do leitor para atribuir um sentido será a base da futura restauração da retórica enquanto prática hermenêutica (COPELAND, 1991, p. 158, 179). 
Dessa forma, a proposta de uma nova forma de traduzir Aristóteles, que postula a representação exata de seu estilo, sendo a sua voz, por meio da reivindicação da representação exata de sua eloquência carrega em si a tentativa da apropriação do pensamento aristotélico pelos humanistas, o que também não é isento de problemas, como a atribuição de sentido apresentada por Copeland.

Bruni trata de contrapor os modelos vigentes na Idade Média, período em que "exatidão" poderia ser sinônimo de fidelidade à ordem das palavras, conforme preconizava Gregório de Nisa (c. 335 - c. 394), como tradução do conteúdo antes que tradução do estilo, de uma forma literal, palavra por palavra, conforme Boécio (480 - 524), ou de literalismo, no sentido de tradução ad verbum, como defende João Escoto (c. 810 - c. 872).

Alguns eruditos, entretanto, se voltaram contra este literalismo, como foi o caso de Anastácio, o bibliotecário, que em carta ao Papa João VIII em 850 critica o excessivo literalismo de João Escoto e acusa a seus contemporâneos de deformar a língua de chegada com as suas traduções literais. Também Tomás de Aquino (1224 - 1274) acusa os literalistas de manterem o cisma entre as igrejas do Oriente e do Ocidente por suas obscuridades. Além dele, Roger Bacon (c. 1214 - 1294) opina sobre tradução na terceira parte de sua Opus maius, intitulada De utilitate grammatica, em que recusa radicalmente a tradução ad verbum e critica com dureza a vários tradutores contemporâneos pelas alterações, asperezas e horríveis dificuldades em suas traduções, a ponto de ele considerá-las incompreensíveis, excetuando a poucos nesta crítica, como Boécio e Roberto Grosseteste, alvo das críticas de Bruni.

Assim, postulando uma tradução ad sensum e orientada pelo estilo, ao buscar reforçar que os textos filosóficos também fazem destacado uso do ornatus, Bruni cita um trecho do Fedron de Platão, ressaltando sua riqueza rítmica e sua eloquência, para ao final ressaltar "o esplendor dos pensamentos, os refinamentos das palavras e o ritmo da composição", e concluindo esta parte de sua exposição: "Se, porém, o tradutor não preserva tudo isso, não se pode negar que comete uma detestável infâmia." (De Interpretatione Recta, I, trad. Mauri Furlan). 
Em relação à Ética a Nicômaco de Aristóteles, Bruni afirma que $\mathrm{O}$ Filósofo busca fazer uso dos ornamentos ao falar de maneira maravilhosa e muito abundante, "a ponto de eu mesmo ser obrigado com frequência a admirar que, em meio às mais sutis discussões, estivesse presente em um filósofo tanto cuidado com estas coisas"7 . Ele também acrescenta: "nem Demóstenes nem Cícero, que se sobressaíram como artesãos das palavras e do falar, teriam exposto melhor este ornamento oratório que foi exposto por Aristóteles." ${ }^{8}$

\section{A contra-refutação de Bruni}

Alfonso de Cartagena(1384 - 1456), no período em que residiu em Basiléia (1434 - 1440), escreveu um libelo contra Leonardo Bruni e sua tradução da Ética a Nicômaco, reiniciando a polêmica contra Bruni, desta vez de um viés mais nacionalista, que contrapunha uma escola de eruditos italianos aos eruditos espanhóis. Entretanto, continuavam no centro da polêmica as estratégias de atualização dos textos clássicos.

O próprio Cartagena havia-se encarregado de traduzir as obras de Cícero sobre a retórica clássica ao vernáculo espanhol nos anos 1427 a 1431. Ciente das dificuldades que a tarefa do tradutor implica, Cartagena havia manifestado sua admiração pelo trabalho de Bruni, chamando-o de noullum Ciceronem (novo Cícero). Segundo Hersberg (2006), Cartagena opta pela tradução ad sensum e rechaça o literalismo, mas relega a um segundo plano o uso da retórica, que pode impedir a fidelidade ao conteúdo.

Como Cartagena não conhecia o grego, parecia a princípio impertinente que ele questionasse a tradução de Bruni. Entretanto, Cartagena não estava julgando a fidelidade da tradução a partir do grego e nem a adequação de se traduzir Aristóteles em latim. De acordo com Beralanga (2005, p. 9) “Bruni traduzia usando o latim de Cícero e esta língua dos estóicos parecia inapropriada para traduzir o realismo ético de

\footnotetext{
7 "[...] ut ego ipse interdum admirari cogar tantam eius rei curam in medio subtilissimarum disputationum philosopho adfuisse." (De Interpretatione Recta, I, trad. Mauri Furlan)

8 "Ne Demosthenes quidem aut Cicero, qui uerborum dicendique artifices existunt, melius hanc exornationem explicassent, quam est ab Aristotele explicata." (De Interpretatione Recta, I, trad. Mauri Furlan)
} 
Aristóteles. Nem sequer Sêneca (...) estava em condições de entender o complexo sentido da virtude aristotélica e suas investigações científicas sobre ela". Desse modo, prossegue Beralanga, "traduzir t'agathon por summun bonum e não pelo singelo bonnum, implicava introduzir toda a moral estóica repentinamente no texto aristotélico, uma escolha cujas consequências teológicas Cartagena não podia aceitar" (BERALANGA, 2005, p. 9).

$\mathrm{O}$ "sumo bem" não era algo a ser alcançado aqui na terra e nem podia ser reduzido a uma questão de virtude. Era a mesma diferença entre delectatio e felicitas. Tratava-se de filosofias de spiritus diferentes que requeriam formas de eloquência distintas, e que não podiam traduzir-se uma pela outra. Assim, acima de uma questão de conhecimento da língua grega estava uma questão pertencente ao logos, à razão humana.

Beralanga (2005, p. 10) então avança que "as traduções anteriores não podiam ser desdenhadas por frivolidade, como fazia Bruni (...) Certamente, nenhuma tradução poderia ser obra de uma injustiça. A superioridade de Bruni, a sua pretensão de encarnar toda a razão, parecia a Cartagena ofensiva." E acrescenta ainda que "o florentino pendia mais pelo estilo do que pelo conteúdo racional da obra (...) Neste sentido, parecia insensato questionar a versão antiga pela rudeza de seu latim. A questão era mais de racionalidade da versão, não a pureza do estilo. Neste sentido, o rigor do latim canônico era contra a vitalidade dos idiomas (...) o que Cartagena pontuava com propriedade".

Um dos resultados deste debate é que, anos depois da morte de Bruni, conforme destaca Botley (2004, p. 59), João Argilópulo (1415-1487) havia decidido retraduzir a Ética a Nicômaco por considerar a versão de Bruni "livre demais e, ao fim do século XV, Battista de Giudici teria questionado se Bruni tinha erudição filosófica para ter empreendido tal trabalho de tradução.

\section{"Aristóteles Eloquente" de Bruni}

Devemos, no entanto, pontuar que a falha de Bruni em incorporar em sua tradução eloquente o spiritus da filosofia por trás da Ética de Aristóteles em 
toda a sua integridade, não advém de seu próprio pensamento, mas de uma demanda por uma tradução latina pautada pela retórica clássica e ciceroniana. Em seu tratado De sui ipsius et multorum ignorantia (11 e 105), Petrarca já reclamava que traduções bárbaras haviam arruinado a eloquência natural de Aristóteles. E a memória deste possível engano humanista (atribuir a Aristóteles um estilo mais pautado pela eloquência do que realmente os textos do filósofo que chegaram até nós parecem sustentar) permaneceu, estimulada pela polêmica contra a filosofia escolástica.

De fato, Marassi (2009, p. 135-136), argumentando sobre a pergunta de Bruni em De interpretatione recta, acerca de se, na tradução da Política de Aristóteles, seria melhor manter termos gregos como "oligarquia", "democracia" e "aristocracia" como se encontravam no trabalho do antiquus interpres ou vertê-los em latim, pondera que hoje "se deve responder que objetivamente tem tido uma fortuna melhor a terminologia de derivação grega e o classicismo, que Bruni quer sustentar, está historicamente superado por expressões menos elegantes, mas que certamente obedecem a regras nem sempre evidentes da história da incidência dos conceitos."

Mesmo assim, com Bruni, estava lançado o desafio a que o programa humanista se propunha: apropriar-se da cultura da Antiguidade não apenas em suas manifestações latinas, mas também gregas e realizar o mesmo em um latim que era adequado para os novos ideais ciceronianos dos humanistas de eloquência, mesmo que nem sempre adaequata no senso filosófico do termo.

A questão de até que ponto a eloquência pode ser atribuída a Aristóteles constitui uma discussão indefinida. As perguntas subsequentes seriam: (1) o que significa "eloquência" para um humanista como Bruni?, e, (2) Quais são as obras em que a afirmação de Aristóteles ser eloquente se baseia? Analisaremos estas perguntas a seguir.

Botley argumenta que as percepções de Aristóteles são sujeitas à modificação pelas novas percepções da língua materna do filósofo. “As considerações de Bruni sobre eloquência de Aristóteles não estariam sustentadas se não fosse pelas opiniões favoráveis acerca dos gregos e da língua grega." Com efeito, ao contrário de Poggio Bracciolini, um outro florentino contemporâneo, que atribuiu a verbosidade à natureza linguística 
grega e não ao defeito estilístico do autor ${ }^{9}$, Bruni, segundo Botley, julgou a eloquência aristotélica com base na concisão do filósofo (2004, p.47-49).

De fato, Florença já deve ter conhecido "o Filósofo eloquente" antes da polêmica em torno da tradução de Bruni. Segundo Botley, Roberto Rossi, um contemporâneo de Bruni, ao traduzir Analíticos Posterirores para o latim em 1406, comentou sobre "a disposição hábil de seu material". Os argumentos de Aristóteles bem construídos e tecidos com força devem se encaixar bem no caso de Bruni. Por isso, a sua tradução tende a fazer com que Aristóteles apresente mais concisão em latim do que em grego (2004, p. 49).

O papel do educador instrutivo dos jovens que o filósofo assume também é um aspecto a qual Bruni dá ênfase. Na obra Vita Aristotelis, de 1429, Bruni entrou na comparação de métodos dos três filósofos gregos: o debate de Sócrates é mais destrutivo do que produtivo; os argumentos de Platão são mais proferidos por pessoas do que por fatos provados; Já as obras de Aristóteles, por sua vez, manifestam uma eloquência esclarecedora, escrita para iluminar as mentes jovens (ibidem).

Em outra obra sua, De Studiis et Litteris, escrita em 1420, Bruni fez menção dos versos de Homero, de Hesíodo, de Píndaro e de Eurípides amiúde citados por Aristóteles no seu trabalho. A habilidade de citar ou fazer alusão aos poetas, segundo Botley (2004, p. 50) é o que Bruni considera, em particular, a eloquência impressionante.

Pelos exemplos, a eloquência, para Bruni, é tanto um estilo oratório desenvolvido ao longo de estudo profundo dos autores clássicos quanto uma habilidade de educar, persuadir, filosofar, transmitir a luz à escuridão.

Porém, segundo Jerrold Seigel (1968, apud BOTLEY, 2004), um intelectual contra o conceito do "Aristóteles eloquente", por um lado, ficamos na dúvida se as obras referidas por Cícero e por Bruni foram as mesmas e, por outro lado, a percepção de Bruni em torno da eloquência de Aristóteles, isto é, sua propriedade, elegância e distinção estilística, é fundamentada apenas pela dedução.

\footnotetext{
9 Segundo Botley (2004, p.48), Poggio se refere a Ciropédia de Xenofonte, uma obra que ele estava traduzindo alguns anos após a morte de Bruni.
} 
Para Seigel, as obras aristotélicas que Cícero analisou são aquelas que tinham sido publicadas nos anos iniciais do filósofo grego e que ainda estavam circulando na época ciceroniana. No entanto, essas obras não circulavam ou haviam sido perdidas antes do séc. $\mathrm{XV}$, mas Bruni adotou os comentários positivos do orador romano para a avaliação das obras aristotélicas em circulação na sua época (apud BOTLEY, 2004, p. 44). Em outras palavras, trata-se de corpora diferentes.

A autoridade canônica de Cícero na eloquência, segundo Seigel (apud BOTLEY, 2004, p. 45), faz com que Bruni confie no julgamento dele sobre o que é ser eloquente e quem domina tal arte oratória. Já que Cícero prestou tamanha homenagem a Aristóteles neste âmbito ${ }^{10}$, pode ser deduzido que Aristóteles é eloquente. As extensivas citações ciceronianas que Bruni fez são criticadas por Alfonso de Cartagena que, conforme mencionamos acima, duvida da propriedade do latim ciceroniano para os conceitos éticos de Aristóteles.

\section{Coluccio Salutati e Bruni}

A concepção de Bruni com respeito à eloquência de Aristóteles, segundo Botley (2004, p. 42-43), já foi estabelecida nos anos iniciais dentro do círculo dos intelectuais humanistas jovens patrocinado por Coluccio Salutati (13311406).

Por volta de 1390, Salutati, o então Chanceler de Florença, encontrou uma versão latina do tratado De remediis irae de Plutarco, traduzida por Simon Atumano (1348-1387). Insatisfeito pelo latim do texto, Salutati empreendeu uma revisão e, a partir disso, produziu a sua própria tradução da mesma obra. Salutati, conforme Botley (2004, p. 6), não conhece a língua grega o suficiente para traduzir diretamente da língua original. A tradução dele, portanto, é apenas uma recolocação artística do texto latino, tornandoo mais elegante.

No prefácio da sua "tradução", Salutati prestou homenagem e louvor aos autores e tradutores pré-medievais cujas traduções, conforme ele mesmo disse, eram "tão bonitas e agradáveis que não necessitariam nenhum

10 Cf. Tusculanae Disputationes, I, 7. "Sed ut Aristoteles, vir summo ingenio, scientia, copia, cum motus esset Isocratis rhetoris gloria, dicere docere etiam coepit adulescentes et prudentiam cum eloquentia iungere." 
refinamento nem esclarecimento" 11 . Essa lista de autores e tradutores carece de personagens medievais (2004, p. 6-7).

A tradução de Atumano não é um caso isolado de que Salutati avalia uma obra escrita em latim pela arte de falar. Em outras ocasiões, ele julgou a De viris illustribus de Petrarca merecidamente louvável pelo seu refinamento estilístico e pela sofisticação retórica, mas não mencionou nada quanto ao papel exemplar na recuperação do gênero de Cornélio Nepos na época clássica (MAZZOCCO, 2006, p. 222).

Com efeito, Salutati, segundo Mazzocco, era o defensor e divulgador mais importante das convicções de Petrarca, o homem que havia aberto o caminho para restauração do estilo literário clássico. E a renovatio litterarum de Petrarca, aos olhos de Salutati, não é mais que renovatio no campo de estilo e da eloquência.

De qualquer forma, há um vácuo descoberto por Salutati: a falta de tradutores que conheçam tanto o latim quanto o grego e que sejam aptos para traduzir de forma igualmente elegante como os precursores. Salutati pode ter começado a busca de talentos qualificados para substituir este vácuo imediatamente após a revisão do tratado. Nada lhe parecia mais fácil do que buscar dentro do seu círculo.

Em 1397, Manuel Crisoloras (1350-1415), o emigrado erudito bizantino, pelo convite de Salutati, permaneceu em Florença para dar aulas de grego. Enquanto isso, Salutati pediu para que Bruni estudasse grego com o bizantino, embora, nesta época, Bruni fosse um estudante de direitos civis e o aceite da oferta implicasse transferência de carreira. Bruni aceitou. É bem provável que, neste momento, Bruni já compartilhasse a mesma visão com o seu benfeitor sobre a importância de estudo do grego.

Segundo Botley (2004, p. 6, 7), Salutati, por certo, sabe como uma boa tradução deve ser, embora ele não possa traduzir pela conta própria os textos em grego. Então, as concepções de Bruni sobre a tradução foram, de certo modo, desenvolvidas sob a influência de um homem que conhecia pouco grego e antes que o próprio Bruni o aprendesse.

\footnotetext{
11 "Non sunt hoc tempore Cicerones, Hieronymi, Rufini, Ambrosii vel Chalcidii, non Cassiodori, non Evagrii, non Boetii, quorum translatione tante sunt venustatis atque dulcedinis, quod nichil posit ornatus vel perspicuitatis in his que transtulerunt desiderari." (BOTLEY, 2004, p. 7)
} 


\section{"Nada foi dito em grego que não possa ser dito em latim"}

Conforme mencionado anteriormente, Cícero é o modelo ao qual Bruni se reporta no que diz respeito à tradução, à retórica e ao uso da língua latina como língua de erudição. No tratado epistolar De studiis et litteris, notamos a maneira em que Bruni exibe, por exclamação, a sua admiração pelo estilo ciceroniano: “Ó Deus imortal! Que eloquente! Que rico! Que bem feito em linguagens! Que exclusivo entre todos os gêneros louvados!"12

No que diz respeito à parte propositiva do De interpretatione recta, Marassi (2009, p. 133) afirma que nas enunciações de Bruni "são retomadas ou ressoam como patrimônio comum de consciência as ideias de Cícero, o qual já sustentava que os conceitos filosóficos podem ser tão bem expressos em latim quanto em grego, que há a necessidade de evitar o uso de palavras gregas não substituíveis pelas latinas e que do ponto de vista da expressão artística, o latim não tem nada que invejar nos textos dos melhores oradores gregos"13

Embora o texto de Bruni em De interpretatione recta seja bastante lembrado pelas polêmicas que suscitou e pelas reflexões que hoje nos propicia quando avaliamos as escolhas dos humanistas quando rompem definitivamente com a tradição da Escolástica, não podemos cometer a injustiça de ignorar as contribuições definitivas que Bruni com ele nos deixou.

Para dar uma estimativa do que ele significou para as gerações posteriores e do que significa para nós, basta que relembremos que o $D e$ interpretazione recta foi retomado por Gianozzo Manetti no seu Apologeticus (1456 - 1459), ou que o confrontemos com as cinco regras do tradutor elencadas por Étienne Dolet em 1540, que decerto retomam uma tradição

\footnotetext{
12 Cf. Craig W. Kallendorf (ed. \& tr.) Humanist Educational Treatises, 2002, p98-99: “Deus immortalis! Quanta facundia! Quanta opia! Quam perfectum in litteris! Quam in omni genere laudis singularem!"

${ }^{13}$ Nesse ponto Marassi se refere as Discussões Tusculanas, de Cicero, onde o mesmo explica por que decide escrever sobre filosofia em latim: “[...] cum omnium artium, quae ad rectam vivendi viam pertinerent, ratio et disciplina studio sapientiae, quae philosophia dicitur, contineretur, hoc mihi Latinis litteris inlustrandum putavi, non quia philosophia Graecis et litteris et doctoribus percipi non posset, sed meum semper iudicium fuit omnia nostros aut invenisse per se sapientius quam Graecos aut accepta ab illis fecisse meliora, quae quidem digna statuissent, in quibus elaborarent." (Tusculanae disputationes, I, 1,The Latin Library)
} 
retórica italiana anterior, podendo mesmo remontar a Bruni (MARASSI, 2009, p. 130).

Assim, ainda que não abarcando e transferindo a filosofia de Aristóteles na totalidade de seu sentido, as propostas de Bruni eram para os tradutores que, dadas as demandas do novo cenário cultural que prenunciava a Renascença, teriam que traduzir as obras de homens como Platão, Demócrito, Aristóteles, Teofrasto, Varrão, Cícero, Sêneca, Agostinho, Girolamo e Latâncio, "em todos os quais é difícil poder distinguir se foi maior a ciência das coisas ou a perícia literária" (GARIN 1950, p. 67).

\section{Considerações finais}

Embora os estudos aqui realizados demonstrem que Bruni realmente tenha se excedido em suas críticas ao antigo tradutor, e que incorreu em erros, embora não inteiramente originados em seu pensamento, conforme apontado por Cartagena e outros, e mesmo a ponto de eruditos posteriores verem a necessidade de uma nova tradução da Ética para restaurar elementos importantes para a tradição de traduções de Aristóteles, cabe ressaltar que Bruni permaneceu muito prestigiado e respeitado até o final de sua vida. Beralanga atesta que ele é "o homem que domina toda a época que se estende de 1410 a $1444 "$, ou seja, até o final de sua vida.

Bruni consegue combater aptamente as acusações de impiedade que pesavam contra ele, removendo habilmente o debate do campo da ética das virtudes para o das competências tradutórias, mas no ponto em que acusa um tradutor supostamente menos apto de estar cometendo "uma detestável infâmia", cabe a ponderação de que "nenhuma tradução decorre de uma injustiça."

A solução preconizada por Bruni para os problemas que levanta repousam sobre uma estudada emulatio do estilo dos homens ilustres, conforme manifestada pelos seus textos em sua língua original, no caso o grego. É notável que Bruni em nenhum momento se reporte à tradição árabe de tradutores e comentadores de Aristóteles, e muito menos aos comentadores do período escolástico, referindo-se somente ao antiquus interpres, que ele não menciona por nome. E neste silêncio transparece a 
ambição de abarcar os clássicos sem considerar a maneira como outros os absorveram.

A afirmação de que "nada foi dito em grego que não possa ser dito em latim" é uma afirmação muito mais retórica do que factual, atribuindo ao latim dos humanistas uma capacidade de recepção que não estava totalmente posta à prova, mas marcando ao mesmo tempo a assimilação da retórica latina clássica, ciceroniana, mais especificamente, do que toda a compreensão do mundo grego.

O seu prestígio e o prestígio de sua tradução da Ética a Nicômaco (embora questionada por muitos) até o final de sua vida atestam como ele permaneceu respeitado e valorizado pelo círculo dos homens ilustres que o conheciam, e o seu tratado De interpretatione recta permanece como marco e como legado para nós de como o trabalho do tradutor passou a ser pautado por valores totalmente renovados, ainda que a princípio tendo tomado o molde dos clássicos.

\section{Referências}

ALIGHIERI, Dante. O Convívio. Tradução, introdução e notas de Emanuel França de Brito. 1 ${ }^{a}$. ed. São Paulo: Penguin Classics / Companhia das Letras, 2019.

BRUNI, Leonardo. De Studiis et Litteris. Tradução Craig W. Kallendorf. In HANKINS, James (ed.) Humanist Education Treatises. Cambridge: Harvard University Press, 2002.

BERALANGA, J.L.V. La fortuna de Cicerón en Castilla hasta la Modernidad. Biblioteca Saavedra Fajardo, 2005.

BOTLEY, Paul. Latin Translation in the Renaissance: the theory of practice of Leonardo Bruni, Giannozza Manetti and Desiderius Erasmus. London: Cambridge University Press, 2004.

CICERO. Tusculanae Disputationes. The Latin Library. Disponível em: https://www.thelatinlibrary.com/cicero/tusc1.shtml. Acesso em 20/05/2019. 
COPELAND, R. Rhetoric, hermeneutics and translation in the Middle Ages - academic traditions and vernacular texts. Cambridge: Cambridge University Press, 1991.

DESLILE, J. \& WOODSWORTH, J. Les traducteurs dans le histoire. Ottawa: Ottawa Université, 1995.

FOLENA, G. Volgarizzare e Tradurre. Turin: Unione Tipografico - Ed. Torinense, 1991.

FURLAN, M. Brevíssima História da Tradução. Parte II: A Idade Média. In: Cadernos de Tradução, v. 2, n. 12, Florianópolis, 2003.

FURLAN, M. Comentário à tradução de De interpretatione recta de Leonardo Bruni Aretino. In: Scientia Traductionis, n. 10. Florianópolis: UFSC, 2011. GARIN, E. Le traduzioni umanistiche di Aristotele nel secolo XV. IN: Atti e memorie dell'Accademia Fiorentina di Scienze Morali la Colombaria. Felice le Monier, 1950.

GELLIUS, Aulus. Noctes Atticae, Liber IX. Disponível em: http://www.thelatinlibrary.com/gellius/gellius9.shtml The Latin Library. HANKINS, J. “Traduire l'Etique d'Aristote: Leonardo Bruni et ses critiques”. IN: Penser entre les lignes. Filologie et filosofie au Quattrocento a cura di F. Mariani-Zini. Villeneuve d'Ascq, 2001.

HERZBERG, Valeria. Apresentação de Alonso de Cartagena, prefácio da tradução da Introducción, en la retórica de Cicerón para o português. In: Mauri Furlan (org.), Clássicos da Teoria da Tradução, Vol. 4 - Renascimento. Florianópolis: UFSC/NUPLITT, 2006.

JOLIVET, J. The Arabic inheritance. IN: A history of twelfth century western philosophy, edited by Peter Dronke. New York: Cambridge University Press, 1988.

KRISTELLER, P.O. El pensamiento renascentista y sus fuentes. Madrid: Fondo de Cultura Economica, 1993.

MARTINS, J.A. Sobre as origens do vocabulário político medieval. In: Trans / Form / Ação, v. 34 n. 3, p. 51 - 68, Marília, 2011.

MARASSI, M. Leonardo Bruni e la teoria della traduzione. In: Studi humanisti Piceni XXIX. Sassoferrato: Istituto Internazionali Piceni, 2009.

MAZZOCCO, Angelo (ed.) Interpretations of Renaissance Humanism. Leiden: Koninklijke Brill, 2006. 
PETRARCA, Francesco. Invectives. translated by David Marsh. Cambridge; London: Harvard University Press, 2008.

\title{
Resumo
}

Este artigo procura analisar Leonardo Bruni, partindo da polêmica em torno da tradução da Ética de Aristóteles, passando pela recepção de Aristóteles na Idade Média, os "erros" que o humanista aponta no "antiquus interpres", a rejeição da tradição escolástica e o investimento dos eruditos do período que precede a Renascença numa tradução eloquente, assumindo o pensamento ciceroniano. Apesar da polêmica entre Bruni e seus opositores amiúde destacada, a ruptura dos humanistas com a tradição Escolástica e a sua proposta por uma tradução eloquente mudaram a forma de traduzir os clássicos.

Palavras-chave: Leonardo Bruni; Tradução eloquente; Aristóteles; Humanistas.

\begin{abstract}
This article attempts to review Leonardo Bruni, starting from the polemic over the translation of Aristotle's Nicomachean Ethics, through the reception of Aristotle in the Middle Ages, the errors the humanist points out in the "antiquus interpres", the rejection of Scholastic tradition and the investment that scholars in the period before the Renaissance make in an eloquent translation, assuming Ciceronian thought. Despite the highlighted controversy between Bruni and his rivals, the breaking up of humanists with Scholastic tradition and their proposal for an eloquent translation changed the way to translate the classical works.
\end{abstract}

Keywords: Leonardo Bruni; Eloquent translation; Aristotle; Humanists. 